\title{
Eementos para compreender a modernidade do corpo numa sociedade racional
}

\author{
Ana Márcia Silva*
}

RESUMO: Este artigo discute a tese de que a Modernidade é o momento de culminância de um processo de separação entre o ser humano e a natureza, e da entrada em cena de um tipo de interesse pelo corpo; fatores esses que têm sua ocorrência com reforço do individualismo e de uma universalização dos valores e normas ocidentais.

Palavras-chave: Corpo, modernidade, natureza, individualismo, ciência

De onde vem o ser humano e, mais, de onde vem o corpo humano? Da terra, responde a mitologia grega.

Prometeu, o titã filho de Jápeto e sobrinho de Zeus, querendo povoar a Terra com criaturas dotadas de espírito, apanha a argila, molha com a água de um rio, e a modela à imagem e semelhança dos deuses do Olimpo. A esse boneco de argila e água, acrescenta a alma dos animais, com suas características boas e más que irão se alojar no peito do ser humano. Atena, deusa da sabedoria, admirando a obra de Prometeu, empresta-Ihe o sopro divino, animando o espírito no interior desses novos seres. O ser humano é aqui, nos mitos do poeta Hesíodo (Schwab 1996), um ser constituído inteiramente de Natureza ao qual se acrescentou o espírito divino; é, portanto, filho da terra, irmão de todos os seres que aqui coabitam.

\footnotetext{
* Professora do Departamento de Educação Física da Universidade Federal de Santa Catarina, aluna do programa de doutorado interdisciplinar em ciências humanas dessa mesma universidade.
} 
Essa gênese humana, semelhante, como se pode verificar, àquela indicada na tradição judaico-cristã, completamente integrada e integrante da natureza e da essência divina, predomina durante milênios na história das mais diversas civilizações. Especialmente no que diz respeito ao trato com o corpo, encontra-se já nos primeiros escritos de que se tem conhecimento, originários da Mesopotâmia de 35 séculos atrás, a idéia da natureza humana como perfeitamente integrada à ordem da natureza e dependente dos desígnios divinos.

O conceito de natureza já possui, em sua etimologia, o sentido da ação de "fazer nascer", proveniente do latim natura, substantivado em nascimento e vinculado ao verbo nasci, nascer, ser nato. Kesselring (1992, p. 20) informa que a raiz indogermânica dessas palavras é gen, com o mesmo significado de nascer, resultar, que daria origem, na língua portuguesa, a palavras como gênese e genitor. A natureza seria, então, responsável por gerar, fazer nascer o ser humano do interior de si própria. Em diferentes idiomas encontram-se essas mesmas raízes que aproximam os termos natureza e gestação, indicando que essa concepção está presente em diversas culturas espalhadas por todo o planeta.

O progressivo desligamento dos seres humanos da totalidade, de uma visão cosmológica, já vinha sendo identificado desde a Idade Média, com práticas de isolamento e preocupação por si, não comuns em períodos anteriores. Não há, porém, indícios de uma separação entre os seres humanos e destes com a natureza que apontassem para uma perspectiva de independência, tal como se verá surgir na Modernidade e que se alargará nessa fase contemporânea. A esse processo de desligamento entre ser humano e natureza corresponderá um tipo muito específico de interesse pelo corpo, que caminha muito mais próximo da dominação e da sujeição, tal como se busca realizar com toda a natureza, do que percebendo-o como um dos fundamentos para uma nova perspectiva ecológica, como se faz necessário nos tempos atuais.

A perspectiva de independência que se verá surgir na Modernidade tem, entre seus fundamentos, o entendimento do indivíduo como um "ser moral, independente, autônomo e, assim, essencialmente, não social" (Dumont 1985). Esse entendimento vai se constituir, concretamente, apenas entre os séculos XVIII e XIX, e ser interiorizado no século XX. A Modernidade é o momento de culminância de um processo em que não só se encontra a separação entre ser humano e natureza, como também a separação, ainda que formal, entre todos os seres humanos que se tornam, desde então, indivíduos. 
Em uma sociedade que se mostra altamente racional e, ainda, alicerçada em um certo dualismo com predomínio das atividades mentais, é intrigante a presença de um interesse por tudo o que diz respeito ao corpo e, mais, por tudo o que diz respeito à aparência a ser apresen-

tada em público. É possível encontrar, ao longo da história da civilização ocidental, muitos indicadores que vão constituindo uma trama, uma urdidura capaz de fornecer algumas luzes sobre a construção desse indivíduo e dessa sociedade que assim se apresentam.

\section{Onascimento do indivíduo moderno e o interesse pelo corpo}

O período no qual vai se caracterizar essa entrada em cena de um interesse pelo corpo e de uma forma específica de trato corporal é identificado com a Modernidade, definida pela "destruição das ordens antigas", pelo "triunfo da racionalidade subjetiva ou instrumental" e pelo "processo de subjetivação" que se forma no interior do individualismo, todos esses termos amparados por uma tendência inédita à universalização de seus valores e normas, levando a uma ocidentalização do mundo. Esses três termos acima definidos serão os guias para a exposição que segue, na tentativa de construir uma narrativa capaz de sustentar a idéia da modernidade do interesse pelo corpo numa sociedade racional, da identificação do indivíduo com sua própria dimensão corporal.

A perspectiva de destruição das ordens antigas pode ser caracterizada esquematicamente em dois aspectos que se apresentam interligados, quais sejam: o fim da perspectiva de transcendência humana e o fim do predomínio aristocrático, marcado pela Revolução Burguesa. O primeiro aspecto pode ser resumido na frase de Nietzsche (1976, p. 211): "Deus está morto!". A crença em Deus foi solapada e "nosso velho mundo há de aparecer dia a dia mais poente, mais desconfiado, mais alheio, mais velho" e tudo porque ocorreu "esse longo acúmulo e seqüência de ruptura, destruição, declínio, subversão, que estão em vista: quem adivinharia hoje já o bastante deles, para ter de servir de mestre e prenunciador dessa descomunal lógica de pavores, de profeta de um ensombrecimento e eclipse do sol". O fim da transcendência é a marca da história do desligamento humano da totalidade, do nascimento de um indivíduo que não crê em uma ordem sobre-humana, a quem não resta outra alternativa senão crer na materialidade manifesta do corpo. 
O ser humano assume, dessa forma, uma nova posição, como resume Kesselring (1992, p. 28): "a situação solitária do homem moderno, fora e além da natureza e abandonado por Deus (de cuja posição ele se apoderou)", Ihe coloca a reflexão sobre a sua liberdade, juntamente com a adversidade das condições concretas de vida, processo esse que vai culminar com a Revolução Burguesa e o fim da aristocracia, como representantes divinos sobre a Terra.

A destruição das ordens antigas vai ser marcada por processos decisivos na história humana: a morte da divindade e o fim do domínio aristocrático. A Revolução Francesa é o marco histórico nesse processo que há muito já vinha sendo gestado e que é aparente em obras como As meninas, de Diego Velázquez, do século XVII: o rei e rainha deixam de ocupar o lugar central no mundo, indicando a gestação de outra ordem social como analisa Foucault (1992). A referência da Corte vai perdendo importância no mundo, que se torna, cada vez mais, urbano e econômico, gerido por outras formas de relação.

O ramo da cultura que permanece vinculado ao pensamento religioso não ficou imune ao processo de secularização do mundo; mesmo no interior do pensamento cristão, pode-se acompanhar a "transformação do sujeito divino em sujeito humano", cada vez menos contemplativo e cada vez mais "um ator, um trabalhador e uma consciência moral" (Touraine 1994, p. 60) e por isso, cada vez mais centrado na materialidade das coisas. A contemplação passa a ser identificada com descanso, para o qual está reservado o "outro mundo". Trata-se agora de envolver-se com o trabalho, entendido como um instrumento de ascese, parte de uma conduta que vai se sujeitando às leis civis e temporais e eliminando "tudo que cheirasse à superstição", colocando-se "contra todas as reminiscências da salvação mágica ou sacramental" (Weber 1985, p. 120). A esse processo que Weber chamará de "desencantamento do mundo", ligado à perda dos componentes mágicos e religiosos, corresponde a ética protestante, que se estrutura concomitantemente ao capitalismo: "quando o ascetismo foi levado para fora dos mosteiros e transferido para a vida profissional, passando a influenciar a moralidade secular, fê-lo contribuindo poderosamente para a formação da moderna ordem econômica e técnica ligada à produção em série através da máquina" (idem, pp. 130-131). Esse indivíduo, caracterizado pela conduta ascética, está muito menos preocupado com as dádivas divinas do outro mundo do que com a construção desse merecimento aqui neste mundo. 
A Modernidade coroada pelas Revoluções Burguesa e Industrial opera, de fato, essa transformação do ser humano em objeto de conhecimento, com um incremento do interesse pelo corpo, com base nas diferentes perspectivas postas na sociedade e nos conflitos de interesses que estão em jogo. Há, em especial, dois focos de atenção, o desenvolvimento de uma medicina privada, formada com base nos interesses do mercado que se estrutura, e o desenvolvimento de uma medicina voltada para o corpo social que se expande. Nesse momento, a ciência e, em especial, uma certa racionalidade desempenham um papel fundamental; as percepções em torno do corpo vão estar profundamente relacionadas com as novas percepções de universo e de sociedade que vão se popularizar a partir dos avanços dessa produção científica.

Para Châtelet (1994, p. 63), é Descartes que vai administrar a revolução na imagem do universo que operam Copérnico e Galileu e lutar pelo reconhecimento dessa física nascente; com essa nova concepção de universo, necessariamente será inaugurada uma nova ontologia, uma nova concepção do ser e da realidade. Sua preocupação essencial não está vinculada à natureza humana, mas sim ao conhecimento: o mundo não tem mais unidade e se transforma num conjunto de objetos oferecidos ao conhecimento humano por intermédio da pesquisa científica, no qual até mesmo Deus só pode ser compreendido pela razão. Em suas "Meditações" (Descartes 1979, p. 99ss), onde se encontra o centro do "cogito", está presente o ser humano que duvida, que pergunta e que, por isso, está separado de Deus e passa a contar apenas consigo próprio. É a autonomia do sujeito cognoscente que fornece o substrato filosófico do indivíduo moderno separado de tudo e de todos; é por sua racionalidade que os indivíduos modernos estão autorizados a se "tornar como que senhores e possuidores da natureza" (idem, p. 63).

Em Descartes, o corpo humano é do domínio da natureza, o corpo é puramente corpo, assim como a alma é puramente alma, princípio que autoriza a razão e a ciência, como sua instituição, a conhecer e dominar o corpo humano, tarefas que serão exacerbadas na atualidade. Ao separar radicalmente as dimensões corpo e alma, a perspectiva cartesiana reforça a idéia de funcionamento corporal independente da idéia de essência, como uma maquinaria ${ }^{2}$ que atua com princípios mecânicos próprios. 0 funcionamento do corpo por esses parâmetros é reproduzido detalhadamente por Descartes em seu Discurso do método, a partir da obra de Harvey, fisiologista do início do século XVII, de quem difere por recusar qualquer recurso às "qualidades ocultas" (Descartes 1979, p. 57) ou inter- 
relações com a alma, fazendo uma descrição da circulação do sangue de forma estritamente mecânica. Isso ocorre porque, para ele, a medicina, juntamente com a moral e a mecânica, são ramos científicos originários do campo da física, vitória da teoria newtoniana, numa perspectiva que estará presente por longo tempo no estudo do corpo humano e que deixa fortes marcas até hoje, inclusive no que diz respeito ao método científico.

A atitude reducionista cartesiana não foi a única que existiu naquele período, sendo que o vitalismo e o ecletismo também se colocavam de forma muito enfática; porém, a hegemonia no interior da ciência coube à primeira. $O$ fundamento comum a essas diferentes concepções é que se mostra de forma intrigante: como se constituiu a necessidade humana de categorizar e, por conseqüência, de separar os fenômenos vitais e a própria Natureza? Qual será essa racionalidade que, potencialmente, já demonstra uma enorme importância aos meios muito mais do que aos fins? Nas palavras de Foucault (1987, p. 154) encontra-se essa preocupação, expressa da seguinte maneira:

Eles [sistema e método] se opõem como se opõem Lineu a Buffon, a Danson, a Antoine-Laurent de Jussieu. Como se opõe uma concepção rígida e clara da natureza à percepção fina e imediata de seus parentescos. Como se opõe a idéia de uma natureza imóvel à de uma continuidade fervilhante dos seres que se comunicam entre si, se confundem e talvez se transformem uns nos outros. Contudo, o essencial não está nesse conflito de grandes intuições da natureza. Está antes na rede de necessidades que nesse ponto tornou possível e indispensável a escolha entre duas maneiras de constituir a história natural como uma língua.

A história natural vai se organizar, inclusive relativa ao próprio ser humano, com base na comparação entre quatro diferentes variáveis, segundo esse autor: a forma, a quantidade, a distribuição no espaço de uns em relação aos outros e a grandeza de cada um. É uma linguagem eminentemente descritiva e que quer fazer "demonstrações infalíveis" como pretendia Descartes à medicina que vai predominar. $\mathrm{O}$ trabalho descriti$\mathrm{vo}^{3}$ das partes dos seres vivos precedeu a decomposição em partes ainda menores, dos órgãos aos tecidos, onde toda complexidade do corpo resumia-se ao arranjo diferenciado dos tecidos, em busca do "elemento explicativo último dos seres vivos", como aponta Almeida Júnior (1995, p. 28), que completa dizendo que "o progresso subseqüente da atitude 
reducionista levará os pesquisadores aos componentes corporais que não fazem parte da experiência do homem comum".

A obra de Pasteur encontra-se nessa mesma fronteira ligada ao reducionismo e à desconsideração da complexidade inerente à realidade. Suas demonstrações sobre a assepsia passaram a interferir nas atividades cotidianas das pessoas, alterando suas práticas corporais concomitantemente com o imaginário higienista que se propagava: a medicina e a expectativa corporal do século XIX se rendem à lógica dos laboratórios.

O triunfo da razão subjetiva ou instrumental vai se dando pela redução da racionalidade a uma de suas facetas - ou a uma de suas faculdades, como diz Horkheimer (1976, p. 12) -, o "funcionamento abstrato do mecanismo do pensamento", capaz de classificar, inferir e deduzir, independentemente do conteúdo em questão e cuja eficiência pode ser ampliada ao ser usada como método. Dessa faculdade devem ser removidos "quaisquer fatores não-intelectuais, tais como as emoções, conscientes ou inconscientes" (idem, p. 17). É essa forma de racionalidade que se encontra na base dos procedimentos científicos e, potencialmente, no discurso filosófico que vai sustentar a Modernidade, tornando-se um de seus elementos fundamentais.

A tendência à assepsia torna-se uma característica também no interior da racionalidade, buscando excluir de si própria os componentes não-objetivos. Essa tendência vai ser extremada no interior do positivismo que propõe, como filosofia e como método, uma ruptura com a imaginação e a argumentação, além de com as emoções, como com tudo que fosse desordenado ou disperso. O método comteano reforça a materialidade do mundo considerando-a, apenas a ela, como digna de investigação por representar o certo e o positivo, sobre a qual os "trabalhos verdadeiramente científicos puderam manifestar a sua exatidão essencial numa ordem inteira de grandes fenômenos", como propõe Comte (1990).

A filosofia do positivismo, especialmente a partir da hegemonia que conquista no âmbito das ciências biomédicas ${ }^{4}$, vai respaldar as ações que serão desenvolvidas a partir do século XIX no âmbito do corpo, seja ele individual ou social. A medicina que se estrutura nesse período vai incorporar o saber oriundo de ciências emergentes, tais como a microbiologia, a anátomo-patologia e as práticas sociais. A atividade dos médicos vai ser fundamental nesse processo de subjetivação que ocorre na Modernidade, com um incentivo especial à identificação do indivíduo com sua dimensão corporal. 
O papel representativo dos médicos nesse processo pode ser bem exemplificado na história dos banhos e das relações com a praia. A água, que até a Idade Média tinha muito mais uma finalidade festiva, ligada mais à diversão e à transgressão do que à higiene, vai modificando sua função ao longo do tempo. Os médicos, a partir do século XV, denunciam a ameaça que os banhos representam, dada a porosidade da pele que tornaria "as superfícies frágeis e as fronteiras duvidosas" (Vigarello 1996, p. 9). Nesse momento do imaginário social ainda está presente uma interação com o todo, o corpo não é visto como uma entidade em separado da natureza e por isso os temores do "mal" que se encontra difuso no ambiente. Com o advento da peste, os banhos públicos e privados desaparecem totalmente nos séculos XVI e XVII por incentivo dos médicos, até que o banho nas casas, como mostra Vigarello (1996, p. 108), venha a se "instalar muito lentamente entre as classes superiores" do século XVIII.

É nesse momento da história que os médicos e higienistas vão exprimir seu receio, juntamente com seu conhecimento científico, acerca dos banhos de mar. Seu discurso vai produzir e codificar práticas ligadas ao mar, visando corrigir os males da civilização urbana: a palavra de ordem é fortificar, a preocupação essencial é repor a energia. Corbin $(1989$, p. 81) vai afirmar que "pouco após a metade do século XVIII, a moda do banho de mar nasce de um projeto terapêutico; os médicos prescrevem uma verdadeira cura inspirada no modelo proposto pelas estâncias termais, então em voga". Com o respaldo científico, a saúde vai imperar sobre o prazer, e os banhos serão sempre rigorosamente prescritos e seguidos de acordo com as ordens médicas.

O banho frio inscreve-se, aqui, numa nova expectativa de corpo. Sua recomendação médica fundamenta-se numa transformação social: "crenças numa força autônoma, inventada por uma burguesia confiante em suas próprias energias físicas, confiante sobretudo em vigores totalmente independentes das filiações e laços sanguíneos" (Vigarello 1996, p. 145). O corpo passa a ser dotado de uma força própria, é uma nova energética que vai abrir caminho para a representação corporal, não mais como matéria inerte, como estruturada a partir do exemplo da máquina a vapor. A perda com a vinculação à alma é compensada pela dinamicidade proveniente da força mecânica que é atribuída ao próprio corpo.

A imagem corporal forjada é coerente com a profunda transformação social que se operava: o individualismo, como expressão ideológica do capitalismo industrial. Reforçar a individualidade humana, percebendo de forma mecânica o funcionamento corporal e cortando os vín- 
culos com a percepção da alma como fonte energética, leva por fim a enfatizar o individualismo das partes do corpo e das partes constituintes da sociedade (Sennett 1997). A perspectiva de movimento apontada pela ciência é a mesma que se estrutura nas sociedades de mercado, com a livre circulação de mercadorias. À noção secular e mundana de indivíduo autônomo e independente em relação ao funcionamento orgânico corresponde a instauração da propriedade privada, característica fundamental dessa nova ordem socioeconômica. O processo de privatização altera, concomitantemente, a estruturação da esfera pública e a organização da personalidade, forçando os indivíduos a se envolverem com as questões do "eu" (Sennett 1988). Também nesse caso, o conjunto da sociedade é mera soma das partes dos indivíduos, e ao Estado cabe exclusivamente a proteção dos indivíduos enquanto tais.

O discurso médico, fundamentado numa perspectiva hierárquica e numa visão conservadora de mundo, reforçará a dicotomia sexual presente e o domínio que lhe corresponde: mulheres, crianças e doentes são imersos abruptamente de cabeça para baixo por um curista encarregado dessas tarefas; aos homens é dado o direito (ou o dever...) de enfrentar as ondas e de demonstrar a esperada coragem e virilidade. Ambos os acontecimentos, porém, têm a ver com as novas tecnologias ligadas ao fortalecimento ou enrijecimento, tão requisitadas naquele período.

As diferenças de gênero são observadas também no que diz respeito à forma de perceber a nudez. No banho de mar, a nudez não é registrada entre as mulheres, mas a nudez masculina é admitida até meados do século XIX; a percepção do próprio corpo, com base nas indicações médicas, vai alterando as expectativas de uma maneira inédita na história, como se pode perceber nesse relato de Corbin (1989, p. 89):

O código estrito do pudor, que começa então a reinar, deixa pressentir a intensidade da sensação, penosa ou agradável. Para uma mulher da burguesia, há algo de extraordinário em deixar a privacy, ainda que seja em uma carruagem de banho, e deparar-se no espaço público, os cabelos soltos, os pés descalços, os quadris à mostra, ou seja, em trajes que se reserva para aquele com quem se escolheu partilhar a intimidade. Para compreender bem isso, é preciso pensar na intensa carga erótica dos tornozelos e da cabeleira femininos. O simples contato dos pés descalços com a areia já representa uma solicitação sensual, um substitutivo não muito consciente da masturbação. Para as burguesas condenadas ao lar, 
mais que para as aristocratas habituadas à vida mundana, a prescrição médica possibilita uma liberdade inesperada, reserva de insólitos prazeres.

Esses sentimentos que parecem predominar na burguesia não são os mesmos que se encontram no banho das classes populares, onde a mistura dos sexos é então permitida. Esse modo popular vai ser, mais tarde, dominado pelo modelo da burguesia com o auxílio imposto das autoridades na manutenção daquilo que se chamou "ordem", ainda que, de fato, o modelo que sobreviverá será uma mescla das atitudes de ambas as classes. A uniformização do banho de mar vai obedecendo a três imperativos importantes: o moral, o terapêutico e a dinamicidade, a partir da acentuação das normas de pudor que, de acordo com Elias (1990), acompanham o processo civilizatório.

Todos os cuidados pessoais implicados nos imperativos morais e terapêuticos constroem um novo esquema de escuta, de apreciação de si mesmo, no qual o corpo se encontra no centro das preocupações. Os interrogatórios médicos, muito detalhados e freqüentes, criam uma estratégia que Corbin (1989, p. 100) irá denominar de uma "obsessiva aritmética de si próprio". Um implemento ao processo de subjetivação, de individuação, já iniciado, será dado com a atenção à sexualidade. Ela, que era discutida abertamente no século XVIII, terá seu foco de atenção alterado no século seguinte, com ênfase nas discussões sobre as desordens, as anomalias e os desvios, que refletem o recato vitoriano que se saiu vencedor, como sugere Roy Porter (1992, p. 313).

A importância que é atribuída ao sexo, ou melhor, ao controle da sexualidade, talvez possa ser mais bem compreendida com a ajuda de Foucault (1986, p. 20), que argumenta que o sexo se transforma, a partir do século XVIII, numa peça fundamental, pois se encontra na articulação entre as disciplinas individuais do corpo e as regulações da população; se constituiu na chave para garantir a vigilância sobre os indivíduos e o controle sobre o corpo social. O corpo passa a ser enfocado pelas "tecnologias individualizantes do poder", por uma anatomia política que atua sobre os indivíduos "até anatomizá-los" (idem, p. 18), tornando-os centrados em seus corpos, com base nas preocupações terapêuticas e morais que vão sendo internalizadas.

As indicações da filosofia e da ciência, assim como as exigências da nova ordem socioeconômica, sobre o funcionamento mecânico atri- 
buído tanto ao corpo quanto às coisas da natureza contribuíram para uma perspectiva secular da vida e para a consolidação de uma imagem corporal presa à materialidade. Nessa civilização material, na qual convém libertar o ser humano da tirania da natureza, o corpo entra em cena em toda a sua dualidade, com a força da sua materialidade que é respeitada como nova instância de reconhecimento do humano e com o obscurantismo de sua natureza que não se deixa apreender facilmente.

\section{Algumas formas de representação do corpo: As alianças entre ciência e arte, medicina e direito, educação e política}

A arte, por sua capacidade intrínseca de representação e materialização do "espírito" de uma época, mostra-se como um elemento fundamental para a compreensão da expectativa de corpo que vai se manifestando na Modernidade. O processo de individuação que vem sendo apontado pode ser percebido nas obras de arte do Renascimento quando surgem os primeiros auto-retratos que, diferentemente do período anterior, começam a ser mais realistas e a não "mascarar" o corpo. Mais do que isso, as obras de arte também apresentam uma tentativa de representação do cotidiano mais elementar, adquirindo uma independência de dois elementos muito característicos das obras anteriores: a representação religiosa ou mitológica e a representação da realeza.

A introdução desse modelo de ciência no domínio da arte se constitui, de fato, num marco decisório em termos de representação corporal. No início do Renascimento francês e italiano, em especial, já se encontram, timidamente, representações do interior do corpo humano e de seu funcionamento; porém, consistiam em obras voltadas exclusivamente para os profissionais da medicina que muito raramente chegavam ao domínio público. No século XVIII essa tendência vai se popularizando, primeiramente por meio da literatura, naquilo que viria a ser chamado de narrativas humanitárias. Thomas Laqueur (1992, p. 241) afirma que o corpo individual, vivo ou morto, adquiriu um "poder próprio", ao contrário do período anterior em que a referência era o "Corpo Universal de Deus" que era representado pelo sofredor que estimulava as ações humanitárias. Nesse século, segundo esse autor, a descrição pormenorizada do corpo (possibilitada pelos avanços das ciências biológicas) se transforma num locus comum, capaz de suscitar a compreensão e a sensibilidade - o corpo era representativo da dor. As narrativas médicas, ainda que 
romanceadas, predominam, mas já anunciam o movimento científico que Laqueur (1992, p. 254) vai chamar de "soberania epistemológica sobre as mentes e corpos alheios", para a qual a literatura será um instrumento poderoso de difusão. Vai se afirmando, gradativamente, a crença de que as ciências biológicas e seus profissionais podem saber mais sobre as ações humanas e seus fundamentos do que as próprias pessoas em questão, as quais têm seu comportamento descrito pormenorizadamente; os recessos íntimos do corpo humano vão sendo revelados, caracterizando, em grande medida, a arte da Modernidade.

A obra de Gustave Flaubert é representativa desse movimento de articulação da ciência e da arte, no interior de uma literatura que é expressiva em seu tempo. Os temas de Flaubert são temas vulgares, visto que os temas demasiado amplos são rejeitados pelos leitores do século XIX. ${ }^{5}$ Esse autor baseia-se nas doutrinas biológicas e médicas do período, trazendo toda a realidade para o interior do romance e tratando de temas correntes como o adultério, como em seu Madame Bovary (Flaubert 1987). Esse romance, enriquecido por toda uma trama de detalhes e procedimentos médicos, tem seu auge na descrição do quadro de sintomas que envolve o suicídio da protagonista, popularizando as últimas descobertas científicas sobre o funcionamento do corpo humano. Em Bouvard e Pécuchet (Flaubert 1981), a ciência é novamente a referência da obra do autor, na qual seus "personagens se debruçam sobre os manuais científicos que tratam dos cuidados de si" (Soares 1998, p. 77), descrevendo detalhadamente e acabando por reforçar a postura e a movimentação corporal pregadas por tais manuais.

A obra de Flaubert, assim como a de Zola, essa última mais propriamente vinculada ao naturalismo literário que subsome a arte à ciên$\mathrm{cia}^{6}$, contribuem para uma expectativa de corpo na Modernidade bastante formalizada, marcada por uma tentativa de objetividade que vai se acirrando gradativamente. Essa forma de arte divulga uma perspectiva de objetivação do corpo, por meio de procedimentos formais de investigação ditados por uma metodologia científica tradicional, que se torna um modelo de compreensão do humano, especialmente no que diz respeito à morte, como aponta Laqueur (1992, pp. 266-267).

A popularização da fotografia, juntamente com a difusão em larga escala do uso do espelho, acentua o interesse dos indivíduos por sua dimensão corporal. O sentimento de individualidade que os historiadores identificam como a emergência do eu no século XVIII vai sendo transformado num sentimento de identidade individual no século XIX, 
com ênfase na identidade corporal: "opera-se então, pouco a pouco, a identificação do indivíduo com seu corpo" (Corbin apud Perrot 1991, p. 423) para a qual a difusão do "retrato", assim como das pinturas de "corpo inteiro", contribuiu largamente.

A pintura é outra das formas de arte que apresenta tendências influenciadas pela ciência, no que diz respeito às formas de representação do corpo. A racionalidade característica da ciência e os conhecimentos por ela produzidos vão gerar formas de arte como o naturalismo racionalista ou o cubismo, em que se poderiam identificar obras como o Atleta, que Picasso pinta em 1909, a qual é representativa de uma nova expectativa de corpo que se estrutura com os fundamentos da ciência.

Essa tendência racionalista vai se encontrar exacerbada em algumas formas de arte contemporâneas que representam o corpo numa perspectiva inédita, denominada "arte anatômica". Essa forma de arte que se expressa como escultura tem no Corredor, de Gunther von Hagens, um exemplo ilustrativo, utilizando cadáveres e novas tecnologias para apresentar uma nova representação do corpo que se mostra seqüencial àquela lógica cientificista já apresentada.

A fotografia é uma das tecnologias possibilitadas pelos avanços da ciência que é utilizada, juntamente com a prática da autópsia, para fins criminalistas: seu uso data de 1876 na polícia francesa, com a finalidade de identificar os criminosos. A medicina contribuirá, de fato, com os juristas, a partir do trabalho de Alphonse Bertillon, que propõe o emprego da identificação antropométrica, com base em cinco ou seis medidas ósseas que foram aprovadas em lei como sendo suficientes para "marcar" um indivíduo (idem, p. 432).

Essa técnica de identificação, que ficou conhecida como Bertillonagem, pode ser compreendida com base na proposição de Richard Sennet (1988, p. 194) sobre a personalidade como imanente às aparências corporais, como parte do processo de identificação do indivíduo com sua dimensão corporal. Essa associação entre características corporais e traços da personalidade já é identificada pelos historiadores ${ }^{7}$ desde o século XIII, porém, é apenas no final do século XVIII que se retomará essa idéia, presente em germe também em Descartes, da "escuta" do corpo: a "cenestesia". Corbin (apud Perrot 1991, p. 438) diz que "deve-se entendê-la como uma percepção interior do corpo" ou como uma "escuta do desenvolvimento das funções orgânicas" e de suas repercussões no comportamento dos indivíduos. A "cenestesia" é, indubitavelmente, de inspiração hipocrática, 
por respeitar as relações do funcionamento orgânico com os elementos da natureza, mas ela acaba por contribuir para que se forme uma representação de corpo presa às aparências e formalizada por uma ciência que investiga e socializa o funcionamento orgânico.

A concepção de personalidade vinculada à aparência corporal vai gerar, num primeiro momento, um recato vitoriano ${ }^{8}$ caracterizado pelo excesso de vestuário, pelo desejo de cobrir-se. Como diz Sennett (1988, p. 218), "a deformação física do corpo por meio das roupas adquire sentido nos mesmos termos: quando o corpo estiver retorcido e fora de qualquer forma natural, deixará de 'falar'”. O reforço a essa concepção virá de novas disciplinas científicas que se estruturam com esse mesmo fundamento, além de técnicas como a Bertillonagem.

A segunda metade do século XIX traz outro nome de destaque, no que se refere aos estudos sobre a forma do corpo e suas diferentes interpretações: Paul Broca. ${ }^{9}$ Para ele, a antropologia só teria sentido se fundamentada em medições, entre as quais as feitas nos crânios deveriam ser privilegiadas, porque só assim seria possível delinear grupos humanos e valorálos com base em suas medidas. Sua valoração foi reconhecida por toda Europa, difundindo a idéia de que os negros representavam um grupo de "inferioridade intelectual e social (...) que jamais foi capaz de ascender à civilização", enquanto os brancos, com cabelo liso e rosto reto, são parte dos "grupos mais elevados na escala humana" (Broca apud Gould 1991, p. 76), apresentando uma imensidade de amostras para confirmar sua tese, apesar das suspeitas que surgiram mais tarde de sua manipulação dos dados. De acordo com Gould (1991, p. 88), não tardou para que Broca reforçasse a corrente da antropologia criminal, com uma série de estudos nos crânios de assassinos, homicidas e ladrões, tornando-se o mestre da craniometria.

Além da evolução da antropologia, esse período é marcado por uma forte tendência no campo das ciências humanas: a quantificação, a fascinação pelos números, a crença de que apenas os números garantiriam a verdade irrefutável. Essa tendência foi encabeçada por Francis Galton, considerado o pioneiro da moderna estatística, que dedicou toda sua vida a propor métodos de quantificação por acreditar que qualquer coisa poderia ser medida. Em 1883 inventa o termo "eugenia", que rapidamente se difunde pelo mundo ocidental e que vai permear o trabalho de inúmeros estudiosos, além dos diferentes projetos políticos nacionalistas.

Entre os estudiosos da antropologia, destaca-se o trabalho de Cesare Lombrozzo a respeito do interior do mundo da criminalidade, que 
se tornou, provavelmente, "a doutrina mais influente jamais produzida pela tradição antropométrica" (idem, p. 122). Lombroso, fundamentado nessa mesma perspectiva de mundo, é influenciado largamente por Comte e pelos princípios do positivismo, aplicando-os ao Direito e criando uma criminologia positiva na Itália. Além da grande valorização dos dados empíricos, característica do positivismo, vai preservar a idéia de hierarquia e, especialmente, dos fenômenos sociais como subordinados aos fenômenos físico-químicos e biológicos, redundando numa igualdade entre o social e o biológico. Luz (1982, p. 171), ao discutir essa questão, acrescenta que Lombrozzo radicaliza essa idéia da identidade entre o social e o biológico, classificando todos os comportamentos "anormais" (loucos, agitadores políticos e criminosos) como anti-sociais e tendo sua causa em anomalias ou taras hereditárias, acrescentando que:

\begin{abstract}
A Ciência positiva chegou até a determinar caracteres orgânicos ligados a determinados tipos de delito. $\mathrm{O}$ conjunto dos caracteres orgânicos "doentes", quando presentes em um indivíduo, constituía o "delinqüente nato". A criminologia positiva de Lombroso foi muito divulgada em sua época. Tinha a característica de propor a substituição das prisões por hospícios, dos juízes por médicos alienistas, dos códigos penais por tratados de psiquiatria.
\end{abstract}

Lombrozzo apresenta, entre seus argumentos básicos, a existência de uma correlação entre os traços dos criminosos e as características dos macacos e dos selvagens, sendo todos criminosos natos. Para isso, faz uma incursão no antropomorfismo, exemplificando com o que ele chamaria de "atos criminosos dos animais" (Gould 1991, p. 124), com a atribuição de claras características e ações humanas, como adultério, violência, esquartejamento, entre outras, às atitudes tomadas por formigas, cegonhas, castores etc. Essa visão de mundo antropomorfisada era a tônica do seu trabalho como perito em julgamentos criminais ${ }^{10}$, e essa era a forma de atuação da escola "positiva" de criminologia, numa clara referência ao fundamento filosófico e à extrema valoração do empírico em seus trabalhos.

Há outras iniciativas na mesma direção, com a obra de Darwin fundamentando a etologia, nova ciência que se dedicará ao estudo dos hábitos e costumes com base nas características humanas, assim como ao estudo dos hábitos animais e de suas correlações ambientais. Surge, tam- 
bém, a frenologia, utilizada mais tarde por Freud, que estuda o caráter e as funções intelectuais humanas, baseando-se na conformação do crânio.

A aliança que ocorre entre a medicina e o direito fundamenta-se na compreensão de um mundo psicomórfico, reforçando a identificação da personalidade com o corpo e a relevância que essa dimensão adquirirá atualmente. A expectativa de corpo que se estrutura nesse período se constitui por um caráter instrumental, na medida de seu uso, enquanto uma dimensão inferior e ligada aos instintos, para o reconhecimento de uma dimensão superior e mais complexa, voltada para as coisas "mentais" ou, mais propriamente, anímicas.

A aliança entre a educação e a política também caminha nessa mesma direção, trabalhando na formação dos novos indivíduos necessários para a ordem socioeconômica capitalista que se estabelece na Modernidade. No século XIX são elaboradas diversas disciplinas somáticas buscando moldar os comportamentos e impor aos indivíduos gestos e posturas adequados às novas exigências sociais. Para Corbin (apud Perrot 1991, p. 607), "a imagem e o uso do corpo, estreitamente subordinados às necessidades socioeconômicas, dependentes de relações de domínio, organizam a pedagogia", ao mesmo tempo em que se verifica um movimento de resistência e emancipação. Esse desejo de liberação do corpo das correções que lhe são impostas, paralelamente à busca de compensação pelas condições da vida urbana e do trabalho, cria uma oposição às iniciativas institucionais de controle dos corpos; de uma perspectiva ou de outra, o que se vê é o ascenso dessa subjetivação do corpo ${ }^{11}$ assinalado pelos historiadores.

Às disciplinas somáticas, a educação "física" dos indivíduos foi necessária, de acordo com Perrot (1988, p. 53ss), para que a nova ordem e a nova racionalidade exigidas pela instauração da sociedade industrial fossem criadas; isso porque era necessário transformar camponeses e andarilhos em operários. Para essa autora, três formas de disciplina criam uma nova corporeidade: a era do olhar, marcada pelas diversas formas de fiscalização; a disciplina fabril, como resultado de uma organização administrativa; e a ciência do trabalho, que tem no corpo um objeto de estudo buscando a maximização do rendimento.

A primeira dessas três formas de disciplina se constitui a partir de uma nova perspectiva arquitetônica como meio para melhor vigiar. $O$ exemplo histórico dessa disciplina está na obra de Jeremy Bentham e em seu famoso Panopticon (1791), no qual o inspetor de uma penitenciária pode "ver 
sem ser visto" (Foucault 1987, p. 77); a questão da disciplina, aqui, fundamenta-se na idéia da interiorização da vigilância, até o ponto em que a própria vigilância não seja mais externamente necessária. Os princípios de visibilidade e vigilância propostos por Bentham são aplicados, também, em outras instituições contemporâneas, como as fábricas e as escolas. A segunda forma de disciplina diz respeito a uma organização específica do trabaIho produtivo, em que o disciplinamento é construído pela divisão metódica e calculada do trabalho com controle do tempo e espaço de cada operação e de cada trabalhador, impregnada por dois outros modelos disciplinares: "o religioso (silêncio) e o militar (hierarquia, disposição em fileiras)" (Perrot 1988, p. 58). A ciência do trabalho é a terceira das três formas de disciplina que se percebem nesse processo de industrialização, de acordo com Perrot. Multiplicam-se as pesquisas dos médicos e higienistas baseadas na "movimentação da máquina humana", procurando conhecê-la para melhor dominá-la e dela dispor. Técnicas e instrumentos como a cronofotografia são utilizados para melhor racionalizar o processo produtivo. Produzir grande quantidade de trabalho com o mínimo de fadiga era o slogan em voga, como Perrot (1988, p. 78) sintetiza: "O corpo torna-se o centro do aparelho produtivo, menos pela sua força, cada vez menos necessária com as máquinas, do que pela sua resistência ao desgaste nervoso. A ergonomia, ou a ciência da fadiga, faz sua aparição."

Instrumentos como a cronofotografia vão, também, ser utilizados por cientistas como Georges Demeny na proposição de métodos ginásticos "racionais", pela decomposição dos movimentos e pelo trabalho regrado com base na eficácia em relação aos objetivos propostos: o movimento corporal passa a ser o fundamento central. A Alemanha é um importante exemplo desse processo de aliança entre a educação e a política que vai se organizar em torno de uma expectativa de corpo. Do final do século XVIII até a metade do século seguinte, o método ginástico proposto por Jahn e por seus sucessores utiliza a ginástica como fator primordial na construção de uma unidade nacional e na emancipação de outros centros europeus, especialmente nas defesas contra Napoleão, procedimento esse que se repetirá até a Primeira Guerra Mundial. Outros países como a Checoslováquia e a França vão registrar procedimentos idênticos; esse "movimento ginástico europeu ${ }^{12 "}$ vai ter seu auge no fim do século passado, com a ginástica tornando-se um "dever nacional" (Corbin, apud Perrot 1991, p. 611), praticada por "batalhões de escolares".

A ginástica como uma disciplina somática, entre outros fenômenos culturais como o esporte, encontra-se, de forma esmerada, no interior de 
instituições como a escola, onde os códigos gestuais de boas maneiras são cobrados ininterruptamente e têm, na prática da ginástica, um componente poderoso. "O corpo é o primeiro lugar onde a mão do adulto marca a criança, ele é o primeiro espaço onde se impõem os limites sociais e psicológicos atribuídos a sua conduta, ele é o emblema onde a cultura vem inscrever seus signos tanto quanto seus brasões", como aponta Vigarello (1978, p. 9): a perspectiva é a da verticalidade. A necessidade do corpo reto e rígido é perfeitamente incorporada pelos objetivos da ginástica, com base nos preceitos da ciência positiva que se expande no século XIX.

A ginástica, por seu "caráter ordenativo, disciplinador e metódico", como indica Soares (1998, p. 19), é constitutiva dessa mentalidade. Para essa autora, o século XIX é coberto de tentativas de estender essa prática à população urbana, sem exceções, já que ela estaria se transformando, por seu número e suas características, num perigo potencial aos objetivos do capital que se expande. Além disso, era necessário controlar os "excessos do corpo vividos por acrobatas e funâmbulos" (idem, p. 19), que ameaçavam as disposições dos higienistas e pedagogos na sua pregação de uma ginástica racional para uma "suposta" obtenção e preservação da saúde, já então compreendida como responsabilidade individual.

A disciplina do corpo, parte do processo de secularização e do novo ordenamento social, não prescindia do controle de nenhuma de suas dimensões: o controle sobre o alimento e o sexo é exemplar. Os médicos e higienistas traçam regimes de vida extensos não mais para atingir o desenvolvimento harmônico tal como na Grécia antiga, mas para obter indivíduos mais servis, criando "um corpo adulto, cuja força e vitalidade fossem a prova do sucesso higiênico", denotando a forte vinculação "ideológica entre o movimento higiênico com a tática de 'estatização' dos indivíduos", como afirma Freire Costa (1983, pp. 178-179).

No interior das escolas, o processo higiênico iniciava pelo ordenamento do espaço e do tempo para agir, centralmente, no controle dos corpos infantis, conferindo a tudo uma dimensão utilitarista: evitar a ociosidade era fundamental nesse tempo. Freire Costa (1983, pp. 184-185) afirma que "a regra de ouro do desenvolvimento físico era a separação por idade e por sexo", especialmente durante a prática de exercícios físicos, para extrair de cada um o máximo de seu rendimento. A ginástica que se difunde com esses preceitos, com suas fortes raízes militaristas, reforça a idéia mecanicista de um corpo constituído de peças às quais se deve prestar a máxima atenção para que as ações sejam sempre mais eficazes. 
Pode-se concluir de tal discussão, que a expectativa de corpo presente na articulação entre educação e política, como nas demais alianças aqui indicadas, acirra a identificação e a concomitante preocupação dos indivíduos com sua dimensão corporal. O trabalho elaborado no interior das escolas desde há mais de um século, assim como em outras instâncias da atividade humana, buscava criar "o hábito de aprender a olhar, admirar e domesticar o corpo próprio desde cedo" (idem, p. 186). Essa denúncia também pode ser encontrada em Foucault (1987, p. 146), sobre o uso de mecanismos como:

a ginástica, os exercícios, o desenvolvimento muscular, a nudez, a exaltação do belo corpo... tudo isto conduz ao desejo de seu próprio corpo através de um trabalho insistente, obstinado, meticuloso que o poder exerceu sobre o corpo das crianças, dos soldados, sobre o corpo sadio.

Para o autor, o poder investiu nos corpos dos indivíduos, ao longo do tempo, criando uma forma específica de consciência de si, ao mesmo tempo em que faz uma exploração econômica. O eixo civilizatório eleito no Ocidente gerou a construção de uma expectativa de corpo fundamentada no reforço de um sentimento contraditório que se vê explodir na atualidade: dominar o corpo e, ao mesmo tempo, libertá-lo; subjugá-lo e depender dele para sua "felicidade"; acreditar na superioridade e na independência da mente, mas se submeter aos rituais necessários ao corpo "em forma".

\section{Notas}

1. Touraine 1994, p. 11 ss. É preciso destacar que, apesar da opção do uso da obra desse autor, sua formulação não é original ou inédita. Em Hegel, por exemplo, já se pode encontrar a idéia da subjetividade como marca da Modernidade.

2. Uma das obras de Julien de la Mettrie - O homem máquina (1982) -, publicada pela primeira vez em 1747, é um clássico da literatura materialista, baseado nesse princípio dualista proposto por Descartes.

3. Essa tendência de subdivisão descritiva que vai se afirmar com Newton coloca-se contra a tradição aristotélica, segundo a qual o todo é sempre mais que a soma das partes. Com o mecanicismo moderno, introduz-se a idéia de que o todo é a mera soma das partes. Dessa forma, conhecendo as partes, se conhece o todo. 
4. Entre os médicos de grande destaque daquele período, que estavam próximos de uma perspectiva positivista ou serviram de fundamento a ela, encontra-se Claude Bernard (1813-1878), considerado o fundador da fisiologia moderna e de quem Comte teria extraído idéias fundamentais para a sua defesa do funcionamento da sociedade (cf. Canguilhem 1982).

5. Charles Baudelaire (1992, p. 48) faz uma análise crítica muito interessante acerca da literatura de Flaubert e de outros autores contemporâneos, apontando para a dissolução da doutrina que pregava a interligação entre o Belo, o Verdadeiro e o Bem e para a pretensão das ciências de ter a Verdade como sua base e objetivo.

6. Canguilhem (1982) cita os trabalhos de Lamy e Donald King sobre as relações entre o naturalismo literário e as doutrinas biológicas e médicas do século XIX, incluindo algumas obras de Nietzsche que apresentariam essa vinculação com a fisiologia.

7. Régnier-Bohler (apud Duby 1990, p. 360) indica, com base em seus estudos da literatura daquele período, que existia uma associação entre as cores da pele e do cabelo com os traços da personalidade, tendo-se o ruivo como violento e usado de forma pejorativa, ou o loiro, que era tido como sinônimo de canônico, elegante e heróico.

8. Porter (apud Burke 1992, p. 310) afirma que recato e decência lembram os vitorianos, "mas o vitorianismo antecedeu em muito àqueles que portam seu nome".

9. Paul Broca (1824-1880) foi médico cirurgião e fundador da Sociedade Antropológica de Paris.

10. Gould (1991, p. 138) cita um depoimento de Lombrozzo, ao participar do julgamento de dois irmãos no assassinato de uma mulher, quando ele teria apontado o "assassino" em razão de ele ter cabeça maior do que o normal, além de mandíbulas enormes e lábios finos, características não presentes no outro; esse foi o condenado.

11. Essas reflexões em torno do processo de subjetivação estão desenvolvidas também em Silva 1996.

12. Denominação empregada por Langlade e Langlade 1986.

\section{Elements to understand body's modernity in a rational society}

ABSTRACT: This paper discusses the thesis that the modernity is the moment of summit of a separation process between human beings and nature, and the appearance of one type of interest in the body factors which have their occurance in the reinforcement on the Individualism and an universalization of the western values and rules. 


\section{Bibliografia}

ALMEIDA JÚNIOR, Antônio Ribeiro de. "A planta desfigurada: Crítica das representações da planta como máquina química e como mercadoria". Tese de doutorado. São Paulo: USP, 1995.

BAUDELAIRE, Charles. Reflexões sobre meus contemporâneos. São Paulo: Ed. da PUC, 1992.

CANGUILHEM, Georges. O normal e o patológico. Rio de Janeiro: Forense, 1982.

CHÂTELET, François. Uma história da razão: Entrevistas com Émile Noël. Rio de Janeiro: Zahar, 1994.

COMTE, Auguste. Discurso sobre o espírito positivo. São Paulo: Martins Fontes, 1990.

CORBIN, Alain. O território do vazio: A praia e o imaginário ocidental. São Paulo: Cia. das Letras, 1989.

DESCARTES, René. Os pensadores. São Paulo: Abril Cultural, 1979.

DUBY, Georg. História da vida privada (2): Da Europa feudal à renascença. São Paulo: Cia. das Letras, 1990.

DUMONT, Louis. O individualismo. Rio de Janeiro: Rocco, 1985.

ELIAS, Norbert. O processo civilizador: Uma história dos costumes. Rio de Janeiro: Zahar, 1990.

FLAUBERT, Gustave. Bouvard e Pecuchet: Obra póstuma. Rio de Janeiro: Nova Fronteira, 1981.

. Madame Bovary. São Paulo: Clube do Livro, 1987.

FOUCAULT, Michel. Microfísica do poder. Rio de Janeiro: Graal, 1986.

. Vigiar e punir: O nascimento da prisão. Petrópolis: Vozes, 1987.

As palavras e as coisas: Uma arqueologia das ciências humanas. São Paulo: Martins Fontes, 1992.

FREIRE COSTA, Jurandir. Ordem médica e norma familiar. Rio de Janeiro: Graal, 1983.

GOULD, Stephen Jay. A falsa medida do homem. São Paulo: Martins Fontes, 1991. 
HORKHEIMER, Max. Eclipse da razão. Rio de Janeiro: Labor do Brasil, 1976.

KESSELRING, Thomas. "O conceito de natureza na história do pensamento ocidental". Revista Ciência \& Ambiente III (5), jul./dez. 1992.

LANGLADE, Alberto e LANGLADE, Nelly. Teoría general de la gimnasia. Buenos Aires: Stadium, 1986.

LAQUEUR, Thomas. "Corpos, detalhes e a narrativa humanitária". In: HUNT, Lynn. A nova história cultural. São Paulo: Martins Fontes, 1992.

LUZ, Madel Terezinha. Medicina e ordem política brasileira: Políticas e instituições de saúde (1850-1930). Rio de Janeiro: Graal, 1982.

NIETZSCHE, Friedrich. Gaia ciência. São Paulo: Hemus, 1976.

PERROT, Michelle. Os excluídos da história: Operários, mulheres e prisioneiros. Rio de Janeiro: Paz e Terra, 1988.

. História da vida privada (4): Da Revolução Francesa à primeira guerra. São Paulo: Cia. das Letras, 1991.

PORTER, Roy. "História do corpo". In: BURKE, Peter. A escrita da história: Novas perspectivas. São Paulo: Edunesp, 1992.

SCHWAB, Gustav. As mais belas histórias da antiguidade clássica. Rio de Janeiro: Paz e Terra, 1996.

SENNETT, Richard. O declínio do homem público. São Paulo: Cia. das Letras, 1988.

. Carne e pedra: O corpo e a cidade na civilização ocidental. Rio de Janeiro: Record, 1997.

SILVA, Ana Márcia. "Das práticas corporais ou por que 'Narciso' se exercita". Revista Brasileira de Ciências do Esporte. Florianópolis: CBCE/Unijuí, 17(3), maio/1996, pp. 244-251.

SOARES, Carmen Lúcia. Imagens da educação no corpo. Campinas: Autores Associados, 1998.

TOURAINE, Alain. Crítica da modernidade. Petrópolis: Vozes, 1994.

VIGARELLO, Georges. Le corps redressé: Histoire d'un pouvoir pédagogique. Paris: Éditions Universitaires, 1978. 
. O limpo e o sujo. Uma história da higiene corporal. São Paulo: Martins Fontes, 1996.

WEBER, Max. A ética protestante e o espírito do capitalismo. São Paulo: Pioneira, 1985. 